\title{
Sonography for hip joint effusion in adults with hip pain
} S M A Bierma-Zeinstra, A M Bohnen, J A N Verhaar, A Prins, A Z Ginai-Karamat,
J S Laméris the hip joint. With sonography, however, even small intra-articular effusion of the hip joint can be detected by measuring the distance between the neck of the femur and the joint capsule. ${ }^{1-3}$ Joint aspiration confirmed that an enlarged ultrasonic distance reflects joint effusion (or sometimes active synovitis without effusion). ${ }^{24}$

Inflammatory joint diseases, such as rheumatoid arthritis and septic arthritis, are often accompanied by joint effusion. ${ }^{4-6}$ In healthy adults on the other hand hip joint effusion is very uncommon. ${ }^{1}$ The prevalence in less severe, or early stage hip disorders is, however, not well documented. We neither know which symptoms nor signs in early or less severe hip disorders relate to joint effusion. Földes et al showed a positive correlation between nocturnal pain and joint effusion in patients from a rheumatology centre and in patients who underwent total hip replacement. ${ }^{7}$ Joint effusion may also have therapeutic consequences. A decrease of the enlarged ultrasonic distance after intra-articular corticosteroid injections in patients with chronic inflammatory joint disease has been shown. ${ }^{4}$ However, as in the other studies on sonography of the hip joint, the patients showed severe or late stage of hip disease, or both.

Before considering a more routine application of ultrasonic investigation in less severe or early stage hip disease, the prevalence of ultrasonic hip joint effusion, and its relation with physical, radiological, and laboratory findings in patients with early stage hip disease should be established. This study investigates these questions in adult patients consulting the general practitioner for pain in the hip.

Conclusion-This study showed a relatively high prevalence of ultrasonic joint effusion in adults with hip pain in general practice. Furthermore the results indicate a relation between joint effusion and clinical signs.

(Ann Rheum Dis 2000;59:178-182)

Department of Radiology, Amsterdam Medical Centre, Amsterdam, the Netherlands J S Laméris

Correspondence to: Dr Bierma-Zeinstra, Department of General Practice, Erasmus University, Room Ff 320, Postbox 1738, 3000 DR Rotterdam, the Netherlands

Accepted for publication 21 October 1999
History and physical examination supplemented with radiological investigation are the usual tools to reach a diagnosis in adults with hip pain, although ultrasonic examination has been added to the available techniques. The diagnostic value of ultrasonic examination of hip joints in children has been extensively studied, but there are few reports on hip joint sonography in adults. Signs of inflammation, such as joint effusion, are not revealed by physical examination, because of the depth of

\section{Methods}

PATIENTS

During 1996 in two general hospitals in Rotterdam, consecutive patients aged 50 years and older with pain in the hip region persisting for one month up to two years, who were referred by the general practitioner for radiological investigation of the hip, were eligible for inclusion. Exclusion criteria were a suspected fracture or tumour on the radiological request, impossibility of history taking or physical examination because of comorbidity, and a hip arthroplasty on the painful side. All patients were asked to give written informed consent. Approval for this study was obtained by the ethical committees of both hospitals. 


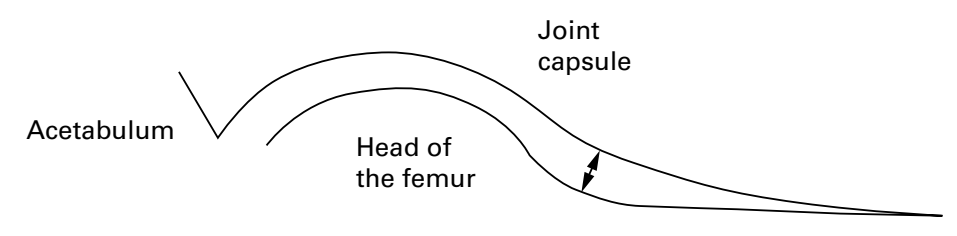

Femoral neck

$\leftrightarrow=$ The distance to be measured

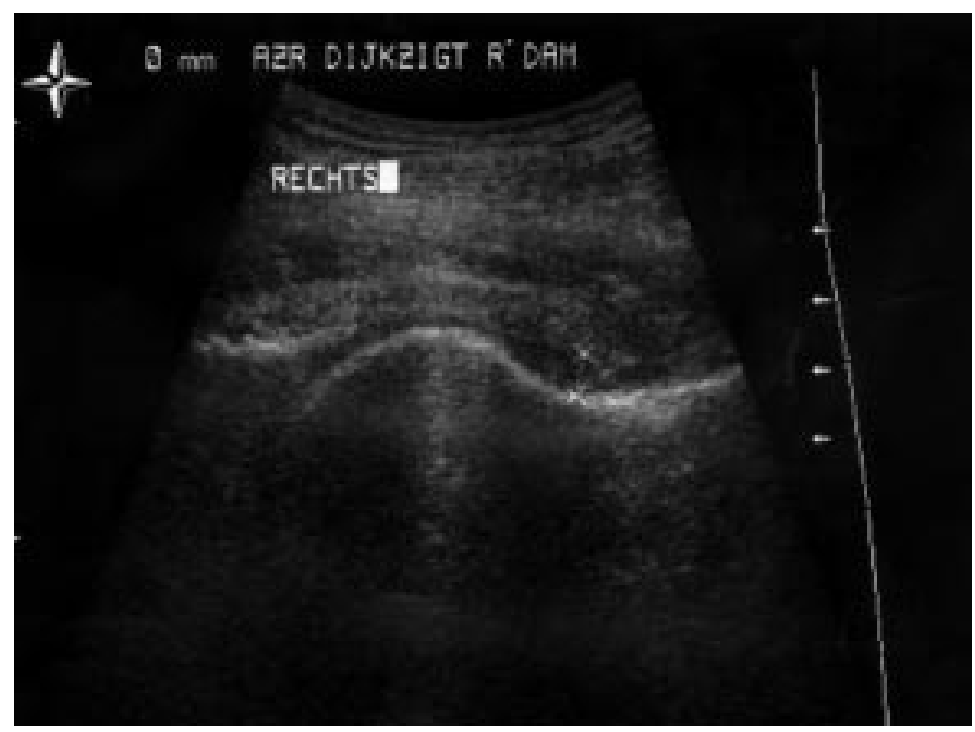

Figure 1 The hip joint as seen during sonographic examination (anterior view).

METHOD MEDICAL HISTORY AND PHYSICAL

EXAMINATION

The medical history and physical examination in all patients were done by one observer and were measured and recorded in a standardised manner. Data concerning pain location, pain endurance, onset and character, pain aggravation, morning stiffness and daily activities were collected. Pain was defined as pain during the past week. The patients had to point out the pain location(s) and specify the location(s) where the pain was worst. Pain severity was determined by a linear analogue scale (zero representing no pain and 10 the worst imaginable pain). Physical examination included pain provocation on palpation and on passive hip movement. Passive hip motion was measured with a two arm goniometer, which had shown equal reliability (intraobserver SD 3.5 degrees) as an electronic inclinometer. ${ }^{8}$ All movements were measured from the zero starting position as recommended by the $\mathrm{AAOS}^{9}$; rotational movements were measured in 90 degrees flexion of the hip. Normal values for range of motion in adults were used to define cut offs for decreased motion and severe decreased motion. ${ }^{10-12}$

SONOGRAPHIC EXAMINATION

Additionally, a standardised sonographic examination was performed. ${ }^{1}$ During this examination the patient was lying supine with the heels together and the hip externally rotated $10-15^{\circ}$. A $5 \mathrm{MHz}$ convex array transducer was applied on the skin in the direction of the neck of the femur. When the joint capsule could be followed from the acetabulum to the point of its fixation to the neck, measurements on a magnified picture on the monitor were made. The measuring points were the lower edge of the capsule and the upper edge of the osseous. The longest ultrasonic intra-articular distance, perpendicular to the joint capsule, from the joint capsule to the femur was measured (fig 1). Intraobserver variability for these standardised measurements were tested in healthy persons (SD of differences $=0.43 \mathrm{~mm}) .{ }^{1}$ In our study all measurements were done by the same investigator, but the ultrasonic images and measurements were checked by an independent radiologist. Non-reproducible measurements because of unclear images were excluded from analysis. An ultrasonic distance of $7 \mathrm{~mm}$ or more, or a difference between both hips of $1 \mathrm{~mm}$ or more, were considered as intracapsular "effusion" in the hip joint (Koski's definition $\left.{ }^{1}\right)$. Another cut off level of $9 \mathrm{~mm}$ or more for hip joint effusion was presented by Sada et al. ${ }^{13}$; we defined this as "major effusion". In children, side difference in ultrasonic distance between both hips has more diagnostic value than a large ultrasonic distance alone. ${ }^{14}$ Therefore, we also defined "asymmetrical effusion" based on only a side difference in ultrasonic distance of $1 \mathrm{~mm}$ or more (the most symptomatic hip compared with the other hip).

RADIOLOGICAL AND LABORATORY EXAMINATION Anterior-posterior radiographs of the pelvis and axial radiographs of both hips separately ("frog-leg" position) were taken. The radiographs were evaluated according to a standardised protocol. The qualitative assessment of radiographic features of hip osteoarthritis was performed by two observers and expressed in the Kellgren score. ${ }^{15}$ Both investigators were blinded for each other and for the results of the physical examination. After assessment of the total sample, consensus was reached when both observers disagreed and this final outcome was used for the analysis. Radiological osteoarthritis in the dichotomous scale was defined as a Kellgren score $\geqslant 2$.

Measurements of joint space distance (superior and axial $)^{16}$ and the diameter of the femoral head were performed by one observer on the anterior-posterior radiograph. Intraobserver variability of these measurements was tested in a representative subset of 30 radiographs.

Increased one hour erythrocyte sedimentation rate (ESR), determined in capillary blood sample, was defined as ESR $\geqslant 25 \mathrm{~mm} 1 \mathrm{st}$ h.

STATISTICAL ANALYSIS

The relation between hip joint effusion according to the three different definitions and other symptoms and signs was tested with logistic regression (effusion as a dichotomy) and with Pearson's correlation test (effusion in $\mathrm{mm}$ ). Radiological osteoarthritis and age showed a relation with several symptoms as well as with hip joint effusion; therefore was adjusted for these confounders. In the group of patients with unilateral hip problems (those consulting for bilateral pain or with ESR $>25 \mathrm{~mm} 1 \mathrm{st} \mathrm{h}$ were excluded), multivariate linear regression 
Table 1 Diagnoses given by the GP to the patients after radiological consultation of the hip

\begin{tabular}{ll}
\hline Diagnosis & $n(\%)$ \\
\hline Hip osteoarthritis & $90(39.6)$ \\
Hip arthritis & $1(0.4)$ \\
Trochanteric bursitis/tendinitis & $22(9.7)$ \\
Neurological disorder & $5(2.2)$ \\
Low back disorder & $18(7.9)$ \\
Contusion hip & $9(4)$ \\
Other & $16(7)$ \\
No diagnosis & $33(14.5)$ \\
Unknown (missing) & $30(13.2)$ \\
\hline
\end{tabular}

Table 2 Presence of radiographic features of hip osteoarthritis in the (most) symptomatic hip according to the Kellgren score in patients with hip pain in general practice

\begin{tabular}{ll}
\hline Kellgren score & $\begin{array}{l}\text { Most symptomatic } \\
\text { hip } n \text { (\%) }\end{array}$ \\
\hline 0-no osteoarthitis & $88(39.6)$ \\
1-doubtful osteoarthritis & $59(26.6)$ \\
2-mild osteoarthritis & $44(19.8)$ \\
3-moderate osteoarthritis & $23(10.4)$ \\
4-severe osteoarthritis & $8(3.6)$ \\
\hline
\end{tabular}

Radiographs of two patients were untraceable.

analysis was used to identify which decreased hip movement (side differences of joint motion as independent variables) is most related to hip effusion (side difference of ultrasonic distance as dependent variable). The predictive value of side differences in range of motion of extension (dichotomy, side difference in extension $>5^{\circ}$ ) in predicting "asymmetrical effusion" was assessed. We used the SPSS+ package for Windows-95; results were considered statistically significant at $\mathrm{p}$ level $<0.05$.

\section{Results}

Of the 244 consecutive patients who were eligible for inclusion, referred by 103 different general practices, 227 gave informed consent. Three cases were excluded because of comorbidity resulting in a study population of 224 patients (164 female, 60 male) with a mean age of 66 (SD 9.6) years. Of the included patients, 29 patients $(13 \%)$ consulted for bilateral hip problems. Table 1 shows the diagnoses of the patients given by the general practitioner after radiological consultation of the hip. The patients from whom we received no information from the general practitioner about the final diagnosis $(n=30)$ showed no different distribution for joint effusion, radiological osteoarthritis or age compared with the other patients. Table 2 shows that $33.8 \%$ of the patients had radiological osteoarthritis in the (most) symtomatic hip, defined as Kellgren score of 2 or more. The qualitative assessment of radiological osteoarthritis showed an agreement between the two observers of $89 \%$ and a

Table 3 Presence of ultrasonic effusion according to three different definitions in patients with hip pain in general practice

\begin{tabular}{lll}
\hline Definition & $\begin{array}{l}\text { Most symptomatic hip } \\
n(\%)\end{array}$ & $\begin{array}{l}\text { Less or } \\
\text { non-symptomatic hip } \\
n(\%)\end{array}$ \\
\hline $\begin{array}{l}\text { "joint effusion" (Koski) (ultrasonic distance } \geqslant 7 \\
\text { mm or side difference } \geqslant 1 \mathrm{~mm})\end{array}$ & $80(37.7)$ & $60(28.2)$ \\
$\begin{array}{l}\text { "major effusion" (ultrasonic distance } \geqslant 9 \mathrm{~mm}) \\
\text { "asymmetrical effusion" (side difference } \geqslant 1 \mathrm{~mm})\end{array}$ & $\begin{array}{l}20(9.4) \\
47(22.7)\end{array}$ & $\begin{array}{l}16(7.5) \\
18(8.7)\end{array}$ \\
\hline
\end{tabular}

$\kappa$ of 0.75 . Blood samples were obtained in 218 patients; the mean ESR was $12 \mathrm{~mm} 1 \mathrm{st} \mathrm{h}$ (range 2-87), 17 patients (8\%) had an increased ESR.

Reliable ultrasonic measurements of the (most) symptomatic hip were obtained in 212 patients and of the less or non-symptomatic hip in 213 patients; this loss was caused by hip arthroplasty (non-symptomatic side: $\mathrm{n}=8$ ), poor ultrasonic visibility (non-symptomatic side: $n=3$, symptomatic side: $n=9$ ), and exclusion by the independent radiologist because of non-reproducible measurements (symptomatic side: $\mathrm{n}=3$ ).

The mean ultrasonic distance in the (most) symptomatic hip was $6.8 \mathrm{~mm}$ compared with $6.5 \mathrm{~mm}$ in the other hip. The prevalence of ultrasonic hip joint effusion is shown in table 3.

There was a significant correlation between the ultrasonic intra-capsular distance of both sides of the hip, even when 29 patients who had consulted for bilateral pain were excluded $(r=0.74, \mathrm{p}<0.001)$. Age was correlated to the ultrasonic distance $(r=0.21, \mathrm{p}=0.002)$; compared with unilateral complaints the correlation was stronger when the pain was bilateral. The correlation was also stronger in patients with radiological osteoarthritis $(r=0.30$, $\mathrm{p}=0.016$ ) but absent in patients without osteoarthritis $(r=0.12, \mathrm{p}=0.155)$.

There was a slight negative correlation between the superior and the axial joint space, measured on the radiograph, and the ultrasonic distance $(r=-0.18, \mathrm{p}=0.01$ and $r=-0.19$, $\mathrm{p}=0.008$, respectively). Intraobserver variability for these joint space measurements was low (SD of differences: $0.26 \mathrm{~mm}$ and $0.23 \mathrm{~mm}$, respectively). Severity of pain, showed no correlation with the ultrasonic distance in the (most) symptomatic hip; neither did the diameter of the head of the femur, measured on the radiograph.

Adjusted for age, "major effusion" showed a positive relation $(\mathrm{OR}=2.6,95 \%$ confidence intervals $(\mathrm{CI})=1.02,6.88$ ) with the presence of radiological hip osteoarthritis (Kellgren scale $\geqslant 2$ ). An increased ESR showed a positive relation with "major effusion" $(\mathrm{OR}=3.8$, $95 \% \mathrm{CI}=1.05,13.90) ;$ an even stronger relation $(\mathrm{OR}=7.8,95 \% \mathrm{CI}=1.69,35.84)$ with increased ESR was found in bilateral major joint effusion, present in nine patients.

Variables from medical history and physical examination, with their significance level in relation to joint effusion in the (most) symptomatic hip, adjusted for age and radiological osteoarthritis of the hip, are presented in table 4. Severe decreased extension $\left(<-5^{\circ}\right.$ or $\geqslant 10^{\circ}$ side difference) showed (adjusted for age and osteoarthritis of the hip) strong relation with "major effusion" and with "asymmetrical effusion" $(\mathrm{OR}=10.2$ 95\% CI $=2.7,47.54$ and $\mathrm{OR}=7.595 \% \mathrm{CI}=1.77,31.57$, respectively). This was not the case for the other joint motions.

With patients with increased ESR and bilateral pain excluded, multivariate linear regression analysis showed that of all hip movements, only side differences in extension was explanatory for side difference in ultrasonic distance 
Table 4 Presence (\%) of variables from medical history and physical investigation in the study population ( $n=224)$ in the (most) symptomatic hip. The relations (odds ratio), adjusted for radiological osteoarthritis of the hip and age, with hip joint effusion according to the three different definition are shown

\begin{tabular}{|c|c|c|c|c|}
\hline \multirow[b]{2}{*}{ Variable (dichotomous) } & \multirow{2}{*}{$\begin{array}{l}\text { Presence in total } \\
\text { study population } \\
(n=224)\end{array}$} & \multicolumn{3}{|l|}{ Odds ratios $(95 \%$ CI) } \\
\hline & & $\begin{array}{l}\text { Effusion defined by } \\
\text { Koski }(n=80)\end{array}$ & Major effusion $(n=20)$ & $\begin{array}{l}\text { Asymetrical effusion based } \\
\text { on side difference }(n=47)\end{array}$ \\
\hline Nocturnal pain & $15 \%$ & $0.8(0.33 ; 1.75)$ & $1.5(0.44 ; 4.98)$ & $0.9(0.38 ; 2.39)$ \\
\hline Morning stiffness & $35 \%$ & $0.9(0.48 ; 1.60)$ & $0.9(0.31 ; 2.35)$ & $1.5(0.74 ; 2.85)$ \\
\hline \multicolumn{5}{|l|}{ Pain onset } \\
\hline After trauma & $8 \%$ & $0.8(0.28 ; 2.31)$ & $1.3(0.26 ; 6.84)$ & $0.4(0.08 ; 1.76)$ \\
\hline After overuse & $14 \%$ & $0.9(0.39 ; 1.97)$ & $0.2(0.03 ; 1.89)$ & $0.5(0.15 ; 1.40)$ \\
\hline \multicolumn{5}{|l|}{ Pain aggravation } \\
\hline By lying on the side & $62 \%$ & $1.9(1.04 ; 3.56)$ & $2.5(0.76 ; 7.96)$ & $2.1(0.98 ; 4.34)$ \\
\hline By walking & $68 \%$ & $1.6(0.88 ; 3.06)$ & $2.1(0.65 ; 6.64)$ & $1.9(0.91 ; 4.12)$ \\
\hline After load & $56 \%$ & $0.9(0.52 ; 1.64)$ & $0.9(0.35 ; 2.40)$ & $1.1(0.56 ; 2.11)$ \\
\hline After prolonged inactivity & $76 \%$ & $1.4(0.71 ; 2.72)$ & $1.3(0.40 ; 4.22)$ & $1.5(0.68 ; 3.48)$ \\
\hline \multicolumn{5}{|l|}{ Location of worst pain } \\
\hline Groin & $22 \%$ & $1.4(0.68 ; 2.72)$ & $1.4(0.46 ; 4.03)$ & $2.5(1.19 ; 5.33)$ \\
\hline Greater trochanter & $31 \%$ & $1.4(0.77 ; 2.63)$ & $1.1(0.39 ; 3.15)$ & $1.4(0.68 ; 2.78)$ \\
\hline Medial thigh & $3 \%$ & $7.4(0.75 ; 72.91)$ & $17.8(2.06 ; 155.66)$ & $2.1(0.33 ; 13.58)$ \\
\hline Anterior thigh & $8 \%$ & $1.1(0.40 ; 2.87)$ & $1.1(0.22 ; 5.33)$ & $1.1(0.32 ; 3.54)$ \\
\hline Lateral thigh & $7 \%$ & $1.4(0.50 ; 4.08)$ & $0.4(0.05 ; 3.44)$ & $0.4(0.09 ; 2.05)$ \\
\hline Posterior thigh & $3 \%$ & $0.3(0.03 ; 2.37)$ & $2.2(0.24 ; 20.73)$ & $0.5(0.06 ; 4.32)$ \\
\hline Knee & $10 \%$ & $0.8(0.31 ; 2.00)$ & $\star$ & $0.5(0.13 ; 1.67)$ \\
\hline Buttock & $29 \%$ & $0.6(1.29 ; 1.09)$ & $0.7(0.21 ; 2.19)$ & $0.9(0.42 ; 1.82)$ \\
\hline \multicolumn{5}{|l|}{ Inspection } \\
\hline Trendelenburg sign positive & $38 \%$ & $1.1(0.62 ; 2.00)$ & $1.1(0.40 ; 2.80)$ & $0.9(0.44 ; 1.73)$ \\
\hline \multicolumn{5}{|l|}{ Pain on palpation present } \\
\hline Iliopsoas muscle & $17 \%$ & $1.0(0.39 ; 1.28)$ & $0.8(0.20 ; 2.85)$ & $0.7(0.26 ; 1.74)$ \\
\hline Gluteus maximus muscle & $40 \%$ & $0.7(0.39 ; 1.28)$ & $1.0(0.37 ; 2.61)$ & $0.8(0.36 ; 1.51)$ \\
\hline Gluteus medius muscle & $41 \%$ & $0.7(0.41 ; 1.33)$ & $1.2(0.46 ; 3.15)$ & $0.8(0.39 ; 1.53)$ \\
\hline Hip capsule in groin & $25 \%$ & $0.9(0.47 ; 1.81)$ & $2.9(1.05 ; 7.56)$ & $2.1(1.04 ; 4.42)$ \\
\hline Inguinal ligament & $30 \%$ & $1.9(1.04 ; 3.59)$ & $1.7(0.62 ; 4.43)$ & $1.5(0.75 ; 3.01)$ \\
\hline Greater trochanter & $61 \%$ & $1.3(0.70 ; 2.25)$ & $1.0(0.36 ; 2.57)$ & $1.4(0.71 ; 2.40)$ \\
\hline \multicolumn{5}{|c|}{ Decreased passive hip joint motion present } \\
\hline Flexion & $44 \%$ & $1.0(0.56 ; 1.77)$ & $1.1(0.41 ; 2.79)$ & $2.2(1.13 ; 4.32)$ \\
\hline Extension & $38 \%$ & $0.6(0.34 ; 1.19)$ & $1.9(0.71 ; 5.01)$ & $2.1(1.08 ; 4.25)$ \\
\hline Abduction & $59 \%$ & $1.6(0.88 ; 2.87)$ & $6.8(1.51 ; 30.58)$ & $2.3(1.12 ; 4.79)$ \\
\hline Addduction & $27 \%$ & $0.9(0.47 ; 1.87)$ & $1.9(0.67 ; 5.25)$ & $1.7(0.78 ; 3.51)$ \\
\hline Internal rotation & $41 \%$ & $1.3(0.74 ; 2.38)$ & $2.6(0.97 ; 7.10)$ & $2.2(1.12 ; 4.31)$ \\
\hline External rotation & $40 \%$ & $1.6(0.88 ; 2.84)$ & $1.1(0.41 ; 2.84)$ & $1.6(0.68 ; 3.94)$ \\
\hline \multicolumn{5}{|c|}{ Painful passive hip joint movements present } \\
\hline Flexion & $65 \%$ & $1.3(0.68 ; 2.32)$ & $3.0(0.83 ; 11.04)$ & $2.0(0.94 ; 4.28)$ \\
\hline Extension & $43 \%$ & $0.8(0.44 ; 1.41)$ & $1.3(0.49 ; 3.37)$ & $1.9(0.98 ; 3.70)$ \\
\hline Abduction & $71 \%$ & $1.4(0.72 ; 2.55)$ & $4.1(0.91 ; 18.77)$ & $1.7(0.79 ; 3.75)$ \\
\hline Addduction & $58 \%$ & $1.1(0.64 ; 2.06)$ & $1.3(0.47 ; 3.53)$ & $1.2(0.59 ; 229)$ \\
\hline Internal rotation & $64 \%$ & $1.8(0.96 ; 3.31)$ & $3.0(0.93 ; 9.80)$ & $1.3(0.66 ; 2.73)$ \\
\hline External rotation & $43 \%$ & $1.9(1.08 ; 3.46)$ & $2.4(0.90 ; 6.61)$ & $2.4(1.08 ; 3.46)$ \\
\hline
\end{tabular}

Statistical signifcant relations $(\mathrm{p}<0.05)$ are shown in bold. ${ }^{\star}$ One cell was empty; no proper estimate of the odds ratio could be made. Flexion: decreased $=<100^{\circ}$ or $\geqslant 5^{\circ}$ decrease in relation to the other side (d). Extension: decreased $=<5^{\circ}$ or $\geqslant 5^{\circ}$ d. Abduction: decreased $=<21^{\circ}$ or $\geqslant 5^{\circ}$ d. Adduction: decreased $=<10^{\circ}$ or $\geqslant 5^{\circ}$ d. Internal rotation: decreased $=<21^{\circ}$ or $\geqslant 5^{\circ}$ d. External rotation: decreased $=<21^{\circ}$ or $\geqslant 5^{\circ} \mathrm{d}$.

$(\mathrm{p}<0.000)$. Other variables from medical history and physical examination added to the model showed no significant explanatory effect. Separate regression analysis for patients with and without radiological osteoarthritis showed that in the group with radiological osteoarthritis the relation is stronger $(r=0.48$, $\beta=0.2, p=0.001$ ).

Table 5 shows to the predictive values of a side difference in extension of more than $5^{\circ}$ for "asymmetrical effusion" in the (most) symptomatic hip, as well as the pre-test and post-test probability for this effusion.

Table 5 Distribution and predictive value of side difference in extension in patients with unilateral problems $(n=163)$. Patients with bilateral pain or increased ESR are excluded

\begin{tabular}{lllll}
\hline & & \multicolumn{2}{l}{$\begin{array}{l}\text { Side difference in ultrasonic } \\
\text { distance }\end{array}$} & \\
\cline { 3 - 4 } & & Absent & Present & Total \\
\hline Side difference in extension & Absent & 120 & 29 & 149 \\
Total & Present & 4 & 10 & 14 \\
\hline & & 124 & 39 & 163 \\
\hline
\end{tabular}

Values are number of patients. Pre-test probability of hip effusion $=24 \%$. Predictive value of negative test: $80 \%(95 \% \mathrm{CI}=0.79 ; 0.86)$. Predictive value of positive test: (post-test probability) $71 \%(95 \% \mathrm{CI}=0.44 ; 0.98)$. Likelihood ratio $=7.9$.

\section{Discussion}

We measured the ultrasonic distance in the same standardised manner that had shown reasonable repeatability. ${ }^{1}$ With final approval of these data by an independent radiologist, we assume the ultrasonic measurements to be reliable.

Although an ultrasonic distance exceeding 7 $\mathrm{mm}$ was found to be abnormal in healthy adults, ${ }^{117}$ a relative high prevalence of joint effusion according to Koski's definition was found in our study population, even in the less or non-symptomatic hip. A definition based on intra-individual side differences in ultrasonic distance showed fewer patients with effusion. In this latter group of patients, as in the group with "major effusion", a stronger relation between joint effusion and clinical symptoms was shown. Given the higher relation with clinical symptoms, we assume that "clinically significant hip effusion" is better reflected by a definition based on intra-individual differences, especially in the case of unilateral problems. The strong relation between major bilateral effusion and an increased ESR might indicate a more systemic disorder. In these 
cases a definition based on intra-individual differences will not suffice.

We were not able to confirm the relation between nocturnal pain or pain severity and joint effusion, as found in pre-operative osteoarthritis patients, ${ }^{78}$ which might be explained by the differences in study populations. In our study, especially decreased extension, but also internal rotation and flexion showed a significant relation with joint effusion independent of age and radiological osteoarthritis. Previous studies $^{18}{ }^{19}$ reported an increase in intraarticular pressure during the same movements, especially with extension and internal rotation. Lloyd-Roberts ${ }^{20}$ demonstrated that the hip capsule is at its tightest during extension, followed by internal rotation and abduction. These authors all assumed that increased intra-articular pressure causes a decreased motion in just these movements. Pearson et al, ${ }^{21}$ studying patients with osteoarthritis of the hip, also found that the initial loss of movement is always in extension and internal rotation, followed by decreased flexion.

In this study, several symptoms from medical history and physical examination showed a relation with both joint effusion and radiological osteoarthritis and existed independently of each other. However, worst pain located at medial thigh and severe decreased extension showed a very strong relation with joint effusion but not with radiological osteoarthritis; therefore, these symptoms may be specific for hip joint effusion. We also demonstrated that in patients with asymmetrical hip problems, a side difference in the range of motion of extension may indicate "asymmetrical effusion", which may be useful in cases where a referral for ultrasonic examination is inconvenient.

Effusion was more often present in patients with radiological signs of osteoarthritis, but was also seen in patients without radiological signs of osteoarthritis. In these cases the effusion may be a preliminary sign of the degenerative process. Therefore, the prognostic value of effusion in the hip joint in patients with early or less severe hip problems, as well as the role of effusion in selecting effective treatment, needs further investigation. In patients with knee osteoarthritis, intra-articular injection with corticosteroids has been shown more effective when joint effusion is present. ${ }^{22}$ However, the effectiveness and feasibility of such interventions in patients with hip osteoarthritis in primary care have not been studied yet. A study comparing non-steroidal antiinflammatory drugs with pure analgesics in patients with knee osteoarthritis ${ }^{23}$ lacked power for subgroup analysis to explore the predictive therapeutic value of effusion shown by physical examination.Therefore, a study in patients with osteoarthritis of the hip should determine if non-steroidal anti-inflammatory drugs are more effective than pure analgesics especially in the subgroup of patients with hip joint effusion (detected by sonography).

We conclude that hip joint effusion in adults with hip pain in general practice is highly prevalent and has a relation with clinical symptoms. However, the prognostic and therapeutic relevance of hip effusion in these patients should be evaluated in future studies before ultrasonic examination of the hip joint can be generally recommended.

We are very grateful to the staff of the radiological departments of Rotterdam University Hospital and of St Franciscus Gasthuis in Rotterdam. Without their help we could not have performed this study.

1 Koski JM, Antilla PJ, Isomäki HA. Ultrasonography of the adult hip joint. Scand J Rheumatol 1989;18:113-17.

2 Wilson DJ, Green DJ, MacLarnon JC. Arthrosonography of the painful hip. Clin Radiol 1984;35:17-19.

3 Rydholm U, Wingstrand H, Egund N, Elborg R, Forsberg L, Lidgren L. Sonography, arthroscopy, and intracapsular pressure in juvenile chronic arthritis of the hip. Acta Orthop Scand 1986;57:295-8.

4 Koski JM, Antilla P, Hämäläinen $M$, Isomäki H. Hip joint ultrasonography: correlation with intra-articular effusion and synovitis. Br J Rheumatol 1990;29:189-92.

5 Wingtrand H, Egund N, Forsberg L. Sonography and joint pressure in synovitis in the adult hip. J Bone Joint Surg (Br) 1987;69-B:254-6.

6 Koski JM. Ultrasonographic evidence of hip synovitis in patients with rheumatoid arthritis. Scand J Rheumatol 989;18:127-31.

7 Földes K, Bálint P, Gaál M, Buchanan ww, Bálint GP. Nocturnal pain correlates with effusion in diseased hips. J Rheumatol 1992;19:1756-8.

8 Bierma-Zeinstra SMA, Bohnen AM, Ramlal R, Ridderikhoff J, Verhaar JAN, Prins A. Comparrison between two devices for measuring hip motion. Clin Rehab 1998;12:496-504.

9 American Academy of Orthopaedic Surgeons. Foint motion: method of measuring and recording. Chicago: American Academy of Orthopaedic Surgeons, 1965.

10 Roach KE, Miles TP. Normal hip and knee active range of motion: relationship to age. Phys Ther 1991;71:656-65.

11 Boone DC, Azen SP. Normal range of motion of joints in male subjects. J Bone Joint Surg 1979;61-A:756-9.

12 Walker JM, Sue D, MilesElkousy N, Ford G, Trevelyan H. Active mobility of the extremities in older subjects. Phys Ther 1984;64:919-23.

13 Harke TH. Hip in infants and children. Clin Diagn Ultrasound 1995;30:179-99.

14 Sada PN, Rajan P, Jeyaseelan L, Washburn MC. Standards for ultrasonographic measurements of the hip joint in Indian adults. Skeletal Radiol 1994;23:111-12

15 Kellgren JH, Lawrence JS. Radiologic assessment of osteoarthrosis. Ann Rheum Dis 1957;16:494-502.

16 Resnick D, Niwayama G. Degenerative disease of extraspinal locations. Diagnosis of bone and joint disorders. 2nd ed. Volume 3. Philadelphia: WB Saunders, 1988

17 Kang B, Zhu T, Du J, Liu J, Chen R, Huang J. Ultrasound diagnosis of effusion of the hip. J Tongji Med Univ 1993;13:156-60.

18 Goddard NJ, Gosling PT. Intra-articular pressure and pain in osteoarthritis of the hip. J Bone Joint Surg (Br) 1988;70B. $52-5$.

19 Eyring EJ, Murray WR. The effect of joint position on the pressure of intra-articular effusion. J Bone Joint Surg (Am) 1964;46-A:1235-41.

20 Lloyd-Roberts GC. The role of capsular changes in osteoarthritis of the hip joint. J Bone Joint Surg (Br) 1953;35-B: 627-42.

21 Pearson JR, Ridell DM. Idiopathic osteoarthritis of the hip. Ann Rheum Dis 1962;21:33-9.

22 Gaffney K, Ledingham J, Perry JD. Intra-articular triamcinolone hexacetonide in knee osteoarthritis: factors influencing the clinical response. Ann Rheum Dis 1995;54: 379-81.

23 Bradley JD, Brandt KD, Katz BP, Kalasinski LA, Ryan SI. Treatment of knee osteoarthritis: Relationship of clinical features of joint inflammation to the response to a nonsteroidal antiinflammatory drug or pure analgesic. J Rheumatol 1992;19:1950-4. 